\title{
Developing eLearning technologies to implement competency based medical education: Experiences from Muhimbili University of Health and Allied Sciences
}

\author{
Thomas Nagunwa \\ Institute of Finance Management, Tanzania
}

\author{
Edda Lwoga \\ Muhimbii University of Health and Allied Sciences, Tanzania
}

\begin{abstract}
This paper provides the practical experience of developing an eLearning technology as a tool to implement Competency-based Medical Education (CBME) in Tanzania medical universities, with a specific focus on Muhimbili University of Health and Allied Sciences. The paper provides a background to eLearning and the early attempt to adopt it in 2006 at MUHAS, with its challenges leading to failure. Next it presents the strategic re-establishment of eLearning to support the new CBME introduced in 2009. Finally, the paper discusses the challenges faced during the implementation process and provides a discussion of lessons learnt. The paper suggests that, in order to improve the quality of medical education in settings with limited resources, universities in developing countries should make effective use of innovative and emerging technologies relevant to their environments. Successful implementation of eLearning requires a strategic approach which should involve university management, academic staff and students. The approach should take into account significant issues including pedagogy, ICT infrastructure, appropriate technologies, human resources, eLearning policy, faculty and student training, integration of eLearning and information literacy as well as the university curricula and partnerships.
\end{abstract}

Keywords: eLearning; competency based medical education; Information and Communication Technology; medical education;

\section{INTRODUCTION}

ELearning has been widely regarded as a new innovative methodology in effectively delivering knowledge and skills, in many disciplines, to large and scattered student communities (Davis et al. 2006). ELearning refers to the use of electronic equipment, computer-based devices and internet based application to facilitate the process of teaching and learning (Nichols 2003; Benninck 2004). ELearning is also called Web-based learning, online learning, distributed learning, computer-assisted instruction, or Internet-based learning (Ruiz \& Mintzer 2006). Using eLearning, students are able to learn at their own pace, at their convenient times, chosen media and learning sequences (Chodorow 1996). It also stimulates active learning whereby students have the freedom to share, discuss and contribute in the process of learning, with their educators and peers (Ruiz \& Mintzer 2006). Educators become facilitators of the learning process rather than deliverers while students become participants rather than listeners (Hamburg, Lindecke \& Thij 2003; Ruiz \& Mintzer 2006).

Learning technologies can effectively be used to implement CBME. CBME has emerged in the health professions to address criticisms of contemporary approaches to training (Frank, Snell, et al., 2010; Ruiz, Mintzer, \& Leipzig, 2006). Competency-based medical education refers to "an approach to preparing physicians for practice that is fundamentally oriented to graduate outcome 
abilities and organized around competencies derived from an analysis of societal and patient needs. It deemphasizes time-based training and promises greater accountability, flexibility, and learner- centredness" (Frank, Mungroo, et al., 2010). CBME is organized around competencies, or predefined abilities, as outcomes of the curriculum (Frank, Snell, et al., 2010). The integration of learning technologies into medical education can catalyse the shift towards individualized (adaptive learning) and collaborative learning, where instructors do not only serve mainly as the distributors of content, but will become more involved as facilitators of learning and assessors of competency (Ruiz et al., 2006).

Studies show that electronic-based learning appears to be effective as traditional instructor-led methods such as lectures in medical diverse education (Casebeer et al. 2008; Curran et al. 2006; Choules 2007; Lwoga 2012; Muhsin 2008; Davis 2006). For example, a study of the eLearning experiences of students in two universities in Ghana revealed that eLearning programmes were "more effective" in comparison to other methods of learning (Adanu et al., 2010). Given the fact that curricular limits clinical students to direct training using real patients, and difficulties in accommodating large numbers of students in hospitals, eLearning can greatly assist the teaching of knowledge and clinical skills. Online learning materials designed with text, images, audios and videos can effectively demonstrate complex medical cases while students can obtain, through video conference, live experiences of operation theatres, Intensive Care Units (ICUs) and other sensitive medical care rooms (Wiecha et al. 2003).

In the past decade in Tanzania's health sciences universities, changes in health care delivery, rapid growth of student enrolment, and a need to transform towards competency based curricula have increased challenges to faculty who are still inadequate to cope with these demands. The health sciences universities are currently faced with a challenge, "to move away from a structure and process-based curricula to competency based curricula that focus on the expected outcomes of the learning activity and the professional competencies that learners are expected to attain" (Ruiz, Mintzer and Leipzig 2006). However, these changes have not been matched with the expansion of existing facilities and development of infrastructure and human resources. With the reduced public funds, Tanzania health sciences universities are forced to find new ways to earn income, to expand infrastructure, cater for a growing number of students, and ensure effective delivery of a competency-based curricula.

Information and communication technologies (ICTs) and eLearning system and services are important means through which most Universities in Africa including those in Tanzania have adopted to improve the delivery of their health sciences educational programmes, and to cope with other challenges. The use of ICT and learning technologies has increased student enrolment and has thus enabled more qualified applicants to access higher education through open and distance learning in Tanzania (Lwoga 2012). In spite of these notable achievements, there is still little research that demonstrates the means through which Tanzanian universities have integrated these learning technologies into their existing curricula. Research shows that the deployment of various learning technologies in Africa is problematic and fragmented (Afifi, 2011; Bitew, 2008).

This paper therefore demonstrates the approach taken in Tanzania health sciences Universities, with a specific focus on Muhimbili University of Health and Allied Sciences (MUHAS) to develop eLearning technology and strategy in an effort to implement the CBME. Challenges experienced so far in the implementation process of eLearning activities are discussed, while the paper, presents lessons we learnt along the way. These will be important inputs for future evaluations and project improvements. Thus, the following aims were posed:

(i) To develop and implement eLearning technology and strategy at MUHAS; and

(ii) To determine challenges and lessons learnt in the implementation eLearning technology and strategy at MUHAS 


\section{EARLY ADOPTION OF ELEARNING AT MUHAS}

MUHAS became a university in its own right in 2007, having previously been a college of the University of Dar es Salaam. MUHAS has also revised its entire curriculum to make it competency based, and introduced innovative teaching methodology. The university currently offers 78 programs in basic, clinical and allied health sciences to over 2680 undergraduate and postgraduate students (Kaaya et al 2011). Muhimbili National Hospital (MNH), the largest hospital in Tanzania, is the only teaching hospital for MUHAS. MUHAS competency based curricula have general competencies expected to be attained by any MUHAS graduate and specific competencies for a particular profession. The general competencies are relationships with patients, clients and communities; clinical skills; professional knowledge; professionalism; relationships with colleagues; working within the system; teaching skills and maintaining good practice (Kaaya et al 2011).

As a public University, MUHAS is mandated to increase its student numbers quite rapidly to meet the country's acute need for more doctors, nurses, pharmacists and dentists. Thus, the number of enrolled students has grown rapidly in the past decade at MUHAS while the number of educators has not kept pace with this rise (Kaaya et al 2011). Teaching support facilities including class rooms, laboratories and ICT equipment do not match the current needs. The teaching hospital, with limited specialists to supervise students and teaching spaces, still provides training in clinical skills for the increased student numbers. For example, a medical specialist at Muhimbili University of Health and Allied Health Sciences (MUHAS) takes an average of 8 students per clinical rotation from the class of 200 compared to 3 students in a class of 50 . The number of offcampus students has increased significantly. Continuing medical education (CME) courses offered by different university units have been increasing over the years, making MUHAS a leading provider of CME training in the country. Now, more than 20 major courses are offered by the university each year, reaching out between 400 and 600 health professions in the country. As the government is now working with medical society to formulate a system of annually accrediting medical practitioners by accumulation of CME points, CME training is potentially going to grow at MUHAS and countrywide.

To bridge the gap between increased numbers of scattered students and limited teaching resources, as well as achieving development of medical competencies among MUHAS graduates in Universities, eLearning appeared to be an important tool. A study in 2009 at MUHAS was conducted to assess the process-competency based curricula. Opinions were gathered from the graduates and their employers across the country on the proposed curricula. The outcome of this study emphasized the need to integrate ICTs into teaching and learning to improve the delivery of learning outcomes (Muhimbili University of Health and Allied Sciences [MUHAS] 2010).

In 2006, MUHAS adopted and implemented a web-based eLearning platform known as TUSK (TUFTS University Sciences Knowledgebase) to enhance learning and teaching at the university. TUSK was established through an academic career award (K07) from the US National Institutes of Health $(\mathrm{NIH})$ as part of curriculum co-development project between TUFTS University in Boston and the African universities. TUSK is an enterprise knowledge and curriculum management system that facilitates the creation, capture, sharing, and leveraging of information to support health sciences education and training (TUFTS 2006).

The eLearning project did not take off successfully due to a number of reasons. Awareness of the significance of technologies in medical education was scant. Because of underdeveloped content development skills, staff were discouraged from creating and uploading content to the TUSK. Further, there was no follow up on the use of TUSK for both staff and students after their training. The internet speed of $512 / 128 \mathrm{Kbps}$ was insufficient to support internet access by the MUHAS 
community of more than 1500 students and academics. Frequent electricity and internet outages frustrated the university community from using online tools and resources for learning.

Experiences from the first attempt became a stepping stone for the strategic implementation of the second initiative.

\section{IMPLEMENTATION OF ELEARNING FOR COMPETENCY-BASED CURRICULA AT MUHAS}

MUHAS made huge efforts in ensuring eLearning was effectively implemented along with competency based curricula in the 2011/2012 academic year. A number of strategies were undertaken by the university to realise this goal as suggested by various scholars (Childs et al., 2004; Schönwald 2003). According to Childs et al., (2004) and Schönwald (2003), effective and sustainable eLearning project needs to be implemented strategically by considering the following issues: management buy-in, eLearning policy, promotion, suitable technologies, cultural aspects of technology adoption, continuous training and improved ICT infrastructure (Childs et al. 2004; Schönwald 2003). Therefore, MUHAS deployed eLearning technologies and strategies in the following phases:

- Awareness creation;

- Improvement of ICT infrastructure;

- Development of policies on ICTs, eLearning and institutional repository;

- Selection and implementation of appropriate eLearning technologies for course management system, student's academic records, digital repository, library automation system, and web 2.0 library services; and

- Creation of awareness and training to change mind set and improve skills of ICT technical staff, students and faculty.

Therefore, these strategies are further described in the following sections.

\section{Awareness Creation}

In ensuring staff and students are becoming aware and enthusiastic on using educational technologies, the university through a collaboration with UCSF made significant efforts on promoting eLearning. During the curricula development workshops between October 2009 and July 2010 in which education experts from UCSF were training MUHAS academic staff in developing, teaching, assessing and evaluating competency based curricula, the experts emphasized the importance of using technology in achieving various objectives of the curricula. They also shared their personal successful stories in using different technologies to run their courses. In the July 2010 workshop, founder and director of education technology at UCSF and one of the most respected people in the medical education technology community in the US, was invited to demonstrate achievements of eLearning at UCSF. He also gave a public talk to MUHAS staff and students on roles played by technologies in medical education. In the same visit, he held several meetings with the university's continuing education and ICT teams, through which he shared UCSF's eLearning experiences especially at the technical side and offered significant advices on successful implementation of eLearning. He also participated in the early stages of designing the MUHAS eLearning strategy.

In September 2010, nine lecturers, a curriculum officer and an ICT expert from MUHAS made a successful visit to UCSF to learn, among other things, effective ways of using technologies for medical education. Similar visit was made by other five lecturers in March 2011. The groups 
shared their experiences and learning with their respective colleagues through, for instance, curriculum development workshops.

\section{Improvement of ICT infrastructure}

Major improvements to the university's ICT infrastructure have been experienced since 2006 . Internet bandwidth has been improved tremendously, from 512/128Kbps in 2006 to the current $8 \mathrm{Mbps}$ (duplex) which is 16 times faster. Fast downloading and uploading of mega files has become possible even at peak hours. Internet access is widely available across the lecture halls, student hostels, the library and other strategic learning areas across campus. All university buildings are connected by a powerful fibre optic network and about 21 hotspots across the campus provide wireless coverage, at least one in each strategic learning area. Nine lecture halls at MUHAS are fitted with multimedia projectors and public address systems to provide lecturers with reliable teaching technology. Equipping similar facilities in other teaching rooms is ongoing. The library also provides access to CDROMs and online databases of medical content, used for learning. Under a recent university library extension project, a multimedia room has been added to facilitate multimedia-related activities, including the creation, recording and storage for teaching multimedia content. The university's immediate plan is to acquire relevant facilities and to hire a full time multimedia expert to coordinate these activities.

Currently, each of 354 academic staff has a desktop computer with internet connectivity while $60 \%$ of almost 2680 students have personal laptops. About $90 \%$ of faculty also have laptops, registered for free access to the internet at the university campus. Four student computer labs are equipped with about 160 desktop computers with internet connection. Recently the university extended the library building to include a new computer lab with a capacity of at least 250 computers. Computer procurement is on-going and the lab is already operational from academic year 2011/2012. About 1000 student laptops have been registered to freely access internet through hotspots on campus.

The operating theatre at MNH is fitted with closed-circuit television (CCTV) that enables students to view operations in the theatres while they are in the hospital's seminar rooms. This capability alleviates the congestion resulting from increased clinical student numbers and provides early exposure to surgical operations for pre-clinical medical students. A distance education network has been built by the Directorate of Continuing Education (DCEPD), connecting MUHAS and Mwananyamala District Hospital through wireless transmitters. This pilot network uses a video conference facility at each end that enables lecturers and students from MUHAS to communicate, learn and share ideas on challenging clinical cases with medical doctors from the district hospital. Currently, a paediatric area has been selected as a focus area and pilot discussions are being coordinated between the experts at each centre.

The Department of Emergency Medicine has developed the electronic clinical simulations, where they employ a life size mannequin that responds to injected drugs and has been programmed to create simulations of life-threatening emergencies. Medical simulators are increasingly being developed and deployed to teach therapeutic and diagnostic procedures as well as medical concepts and decision making to medical students across the world. Simulators have been developed for training procedures ranging from the basics such as blood flow, to laparoscopic surgery and trauma care. Simulations provide health professional students with sufficient opportunities to develop both the practical knowledge and the technical skills that are needed in real-world clinical situations involving patients than other types of learning technologies such as power point projectors and white boards. They further adequately mimic real-world, patient health care events characteristic of those found in physician office, clinical and hospital environments than other types of learning technologies, thus consolidating competency-based training. At MUHAS, use of digital simulations and skills laboratories has immensely contributed to 
implementation of CBME by being able to deploy ICT to enhance teaching and learning experiences, and expand knowledge via online learning opportunities.

\section{Development of policies on ICT, eLearning, and institutional repository}

Existence of policy to guide the use of educational technologies is an important aspect towards promotion of the tools as well as ensuring proper management and use of the technologies within pedagogical limits. In this regard, parallel to the implementation of the technologies, the university is reviewing the ICT policy to incorporate the elearning issues. The reviewed ICT policy will be operation in 2013. The University has also developed an institutional repository in 2012, separate from the existing general ICT policy. The reviewed ICT policy aims to enhance the use of technologies for teaching, learning and research purposes. It will address issues regarding administration, curricula, content, capacity building, copyright, security, code of conduct and privacy, infrastructure, promotion and reward, partnerships, evaluation and monitoring of eLearning systems at the university. The policy will encourage educators and students to use eLearning by specifying favorable environment to enhance use of these technologies, such as facilities, information resources, and technical human resources. The eLearning activities are now managed by the Directorate of Information and Communication Technologies (DICT) at the Educational Technology, Research and Development section as specified by the DICT strategic plan.

An institutional repository policy was also developed to enhance the visibility of research outputs produced by the University including theses and dissertations, technical research reports, preprints and post-prints articles and other grey literature. The policy addresses aspects including administration, specification of data to be preserved, submission and withdraw guidelines, intellectual property rights and access control. It requires the Directorate of Library Services (DLS) to work with the Directorate of Research and Publication (DRP) and DICT to coordinate the use of the repository and implementation of its guidelines.

\section{Selection and Implementation of appropriate eLearning technologies}

Selection of eLearning technologies relevant to the MUHAS environment was a key step in the implementation process. Different criteria were used to guide selection of a specific technologies including cost (preference was given to open source), easy availability of supporting resources, ease of training and adaptation by MUHAS community, usefulness to different university groups and their capability to be supported by the university's limited ICT infrastructure. The most important of all was the capability of the technology to support pedagogy and competency based curricular at the University.

Moodle open sources software was therefore selected as a course management platform for effective management of courses as well as provisioning of virtual interactions between educators and students. Moodle was selected because of its capability to manage courses, free license and has a largest user community comparing to any content management system. Implementation of the platform was completed in early 2012 and it is to be used in the first semester of the 2012/13 academic year, starting with all first year undergraduate students in the information and learning technologies course (IT 100). This course (IT 100) is taught to all first year students at MUHAS, with aim of imparting necessary skills on the use of various technologies to support learning and access to relevant literature.

Web 2.0 technologies were also integrated into the Moodle platform to enhance collaborative learning among students. Web 2.0 refers to the "social use of the Web which allows people to collaborate, to get actively involved in creating content, to generate knowledge and to share information online" (Grosseck, 2009). Web 2.0 or social media tools improve information sharing, 
communication, interoperability, participation, and user-focused design (Carpan, 2010). Web 2.0 technologies can support constructivism-oriented pedagogical approaches such as active learning, social learning, and student publication, by providing environments and technologies that promote and foster these interactions (Lwoga 2012). These technologies include blogs, wikis, social networks (facebook and twitter), podcasts and Google docs. MUHAS has therefore integrated blogs, wikis, discussion forums, instant messaging features into the eLearning platform. The web 2.0 tools also form part of the information and learning technologies course that is taught to all first year undergraduate students in their first semester.

In the same year 2012, the University also implemented a student academic record information system namely SARIS to support the administration and delivery of students' academic records such as exam results, timetable, and other students course information. This system has improved access to students' academic records, management of course information, examination results and management of timetable and venues.

A key element in promoting distance learning within and outside the university community is the collection, preservation and distribution of scholarly works, projects and research performed by faculty and students. The university has recently established an institutional repository through the use of DSpace software. DSpace is one of the leading open source products, has the largest community and therefore widest access to support. It supports a wide variety of data, including books, theses, three dimensional digital scans of objects, photographs, film, video, research data, applications and simulation models.

The university library provides access to a wide range of online academic databases and CDROMS for learning and teaching activities. The library has automated its services, and therefore its catalogue is available online through the library website. This online public access catalogue (OPAC) provides access to bibliographic details of books, journals and CDROM that exist at the library. The university is also a member of a consortium of Tanzanian universities and research libraries (COTUL) through which it has a subscription to over 44 online libraries, including African Journals Online (AJOL), Cambridge University Press (CUP), Edinburgh University Press (EUP), Oxford University Press (OUP), and others. The library website also provides access to annotated links of online resources health sciences including e-journals, e-books, e-theses, evidence-based resources, online educational resources, and many others. The library also developed social bookmarks by using an external service namely delicious to manage library information resources of more than 100 annotated web links. The use of delicious has enabled more efficient access and retrieval of health scholarly literature at the University than spiders and search engines because they do not have the human capability to conceptually identify and evaluate the web page's subject. Further, the library has also developed a Google custom online search tool for searching subscribed e-journals and e-books at MUHAS, and it is embedded at the library blog.

The library has also established a downloadable library toolbar to allow single click access to a wide range of library collection and enhance use of library services at MUHAS. This toolbar was developed with the help of Conduit (www.conduit.com). The single-click library toolbar contains several products and services provided by the library, which include a link to MUHAS library website, google web search, library catalogue, digital library services (institutional repository, latest e-resources, theses, educational resources, CDROMs, and online tutorials on information search techniques), subscribed e-journals (HINARI, Annual reviews, CABI Direct, Cochrane, Emerald), library blog, and library social networks (twitter and facebook).

The library website is also integrated with other various web 2.0 technologies to enhance access to information resources and promote library services at the University. These tools include blog 
and social networks such as facebook and twitter to enhance access of information resources such as new books and promote library services and events including workshops.

\section{Training of ICT and eLearning technical support staff}

In the past three years, the university has increased the number of ICT technical staff from 4 to over 11 in its various units. The DICT staff support the whole MUHAS ICT infrastructure, as well as eLearning services at the five schools, two institutes, and seven directorates. The number of ICT technical staff is expected to increase to support eLearning activities more efficiently. All technical staff at DICT were trained on the eLearning concepts, content development, and the management and use of different eLearning software including Moodle, SARIS, DSpace, ADLIB library automation system, and other web 2.0 tools. Various in-house workshops were conducted at MUHAS to equip these technical staff with appropriate skills in this area. Similar in-house workshops on various ICT aspects are also continuously organized by the Directorate of ICT in order to update their knowledge and cope with the rapid advancements of technologies. Some technical staff also attended short courses on various ICT aspects outside the University. Plans are on-going to take two ICT for further postgraduate programmes on ICTs.

\section{Training of faculty and staff in eLearning technologies}

The university has taken initiatives to create awareness and train faculty and students in the use of eLearning technologies. To create awareness of the eLearning technologies, the DICT and library took the following steps: conducted voluntary workshops on eLearning and information literacy aspects to faculty and students; integrated eLearning and information literacy (IL) into university curricula where all first year undergraduate students are taught this course from 2011/12 academic year; posted online tutorials on eLearning and information literacy aspects at the library's homepage; created links of all eLearning sources at the library's homepage; and informed academic staff about the existence of eLearning technologies through the university group emails.

The DICT has recently trained more than 20 lecturers and 17 postgraduate students from different schools and directorates on the use of Moodle platform. More than 80 faculty form different schools have also been trained on the use of SARIS. Furthermore, the library regularly conducts training on information literacy and evidence based practice to faculty. For instance, in 2011, the library conducted seven workshops to academic members of staff, and eight workshops to students where a total of 100 academic staff and 60 students were trained.in Web 2.0 tools and sharing methods, evidence based practice, online search strategies, online reference management. For instance, in one of the workshops, which attracted 35 scientists from 8 health universities and research institutions including MUHAS, most participants (92.9 percent; $n=26$ ) reported that the objectives of the web 2.0 workshop were met. Participants felt that all sessions were useful because they improved their knowledge on online searching; preparation of teaching materials through wiki; and using social bookmarks to manage citations and references. Generally, similar training workshops are being conducted for the other academics, undergraduate as well as postgraduate students this year.

\section{Development of eLearning and information literacy curriculum}

The university has introduced a new course on information and learning technologies in the new curricula in order to build students' capacity in managing and using eLearning technologies. The module, Information and Learning Technologies (IT 100), is divided into two sub-specialties, learning technologies and information literacy and. The first module, eLearning technologies aims to impart knowledge and skills to student in regard to the use of basic ICT, such as operating and application systems, and use of eLearning system for preparing and completing university 
assignments, as well as the use of web 2.0 technologies including blogs, wikis, social bookmarks and Google docs for collaborative learning. The second module, information literacy focuses on the access and use of scholarly electronic resources for assignments, or clinical problem, or research, as well as online reference management systems. The course is taught in the first and second semester to all first year undergraduate students across all schools.

A study was conducted in May, 2012 to assess whether first year undergraduate students are applying the research skills taught in information literacy (IL) module in course IT 100 to their work in other classes and for anything unrelated to class at MUHAS. A questionnaire survey was physically self-administered to 106 first undergraduate students who comprise thirty percent of the total student population $(n=356)$ in 2012. The study demonstrated that students continue to use the skills gained during the IL course both in other classes and for anything unrelated to class, such skills included one keyword searching technique, Boolean operators, phrase searching and truncation and/or wildcards. However, there was low use of scholarly databases and library catalogue for academic and non-academic activities. These findings show a need to address some issues concerning the information literacy module (IT 100.2), such as an increased emphasis on teaching topics related to search strategies, information sources and evaluation of resources as a practical and useful skill. The study findings further showed that issues related to facilities (internet connectivity and electrical power) will also need to be addressed. In general, first year undergraduate students may have a way to go, but this assessment indicates that they are making progress. The study findings further specified that a careful and rigorous approach to assessment can provide the basis for appropriate corrective action.

\section{CHALLENGES FACED IN THE ELEARNING IMPLEMENTATION PROCESS}

MUHAS still experiences difficulties with the utilization of eLearning technologies. Such barriers include lack of access to computers, slow internet connectivity, electrical power outages, lack of awareness and ICT literacy skills among faculty and students, and inadequate number of technical ICT staff.

Firstly, there are still inadequate numbers of computers to meet the growing number of students at the University. With the current number of desktop computers available in computer labs is 160 , the student to computer ratio of $1: 15$ is still far from achieving a successful long term eLearning strategy, given the annual increase in student enrolment. A study of the deployment of learning technologies in Tanzania public Universities also revealed that limited number of computers led to difficulties in setting up practical examinations and computer-administered examinations (Lwoga 2012). Most computers were prone to mechanical wear and tear due to virus problems, dust and frequent power outages (Lwoga 2012). Private laptops owned by students have temporarily reduced the gap. However, MUHAS has been acquiring new partnerships with local and international organizations to improve the situation. For instance, in 2009, the university received funds from Tanzania Education Authority (TEA) to acquire 86 new computers.

Secondly, the internet speed is still not satisfactory to effectively support eLearning activities. The current bandwidth capacity of $8 \mathrm{Mbps}$ (duplex) is still not sufficient for effective internet use in learning, given the size of the community. During the peak hours, downloading files of a few megabytes could take up to half an hour, while larger files could take an hour. The current capacity is between $15-20 \mathrm{Mbps}$. Other African studies also reported similar barriers that University and research communities are discouraged to ICTs for teaching and learning due to slow internet connectivity, such as in Nigeria (Ezeani, 2011), Kenya (Kwanya, Stilwell, \& Underwood, 2012) and Tanzania (Muneja \& Abungu, 2012). Currently, MUHAS is making efforts to increase bandwidth to enhance the use of ICTs for teaching and learning activities. Further, 
through the Ministry of Education's project on provision of high bandwidth capacity to higher learning research institutions across the country, MUHAS' capacity is expected to increase to $25 \mathrm{Mbps}$ by the end of phase 1 of the project in October 2012 (Ministry of Communication, Science and Technology 2012).

Thirdly, the electricity power distribution national network is another difficulty to eLearning activities at MUHAS. Generally, only 10 per cent of Tanzania's population is connected to the national electricity grid. Town dwellers are the main consumers of electricity, while rural grid electrification is less than 1 per cent of 8,600 villages in the country (Lema 2004). There has also been power rationing since 2006 in the country, which has posed a great challenge to universities in the implementation of eLearning tools in their institutions. However, MUHAS has taken various initiatives to improve the situation. For instance, the University has installed the solar power panels at the library and ICT directorates to enable students to have access to information materials and learning technologies despite the power outages. Other initiatives are still on-going to install alternative sources of power in other strategic learning areas at the University.

Fourthly, lack of awareness and internet skills inhibits most students and faculty to use the eLearning technologies at the University. Similar findings were observed in other studies that most students and faculty had little or even no experience in using ICTs such as in Nigeria (Rhema and Miliszewska, 2010), and other higher learning institutions in Tanzania (Bakari et al., 2010; Lwoga 2012; Ndume et al., 2008). In this paper, ICT was not taught as a basic course to most students at the University with exception to the Nursing Bachelor programme students in the past years. However, this situation has been alleviated by developing a curriculum on information and learning technologies, which includes web 2.0. This course is currently taught to all first year undergraduate students. Periodically, through the ICT and library directorates, faculty development programmes are organized to enhance the use of learning technologies including SARIS, Moodle, information literacy skills and web 2.0 to support teaching and learning. Therefore, we expect that more faculty and student will use learning technologies as the awareness and literacy levels increase at the University.

Lastly, although there is a pool of trained ICT and library staff at University, their number is small and does not adequately support the needs of the learning technologies. The deployment of learning technologies has increased demands on ICT staff because they need to manage learning technologies in addition to their existing ICT functions. Other studies of other higher learning institutions in Tanzania (Bakari et al., 2010; Lwoga 2012; Ndume et al., 2008) also revealed similar findings that delays in the installation, operation, and maintenance of equipment and software were mainly contributed by the inadequate numbers of technical ICT experts in these Universities. In this paper, the university is currently taking initiatives to increase the number of ICT technical expertise as well as to provide adequate training for these personnel to ensure smooth running of ICTs including learning technologies.

\section{LESSONS LEARNT}

Challenges experienced by the university in both the first and the on-going eLearning development project have given a number of lessons to learn which could be useful in the future expansion of the project and as a learning experience to other academic institutions.

Promotion of educational technologies in the medical oriented community is a key initial step in the eLearning implementation process. Promotion strategies such as public seminars/talks on educational technologies, and the use of university website to publicize interesting technologies and successful stories in the use of eLearning in the medical field could play a significant role. A 
small group of young lecturers and students who are enthusiastic in technology can be trained as eLearning champions and used as ambassadors of eLearning in the university community.

Building partnerships with other medical institutions which are advanced in the use of ICT in the provision of medical education could also be a key step. Through this strategy, the institution gains a chance to learn about other institutions' experiences, common challenges, and lessons learnt as well as the technologies they adopted. MUHAS-UCSF collaboration provides a stand out example in this case.

Successful implementation of eLearning relies greatly on the university administration's support for ICT and eLearning. The administration should be convinced of the benefits of eLearning and involved from the beginning of the strategy implementation process. Positive support implies the commitment of the administration in financing the implementation process and promoting the use of ICT among the university community. ICT and eLearning policy are important tools to ensure that the eLearning initiative is successful. An effective eLearning policy should state the responsibilities of the administration, staff and students in ensuring appropriate, legal and effective uses of the technologies in line with pedagogy.

Evaluation of ICT infrastructure requirements for eLearning should be carried out to identify areas which need to be improved. Capable and reliable ICT infrastructure, including computers, bandwidth capacity, accessible and well distributed network should be in place before implementing eLearning technologies.

Many educational technologies (e.g Moodle for course management, Elluminate for web conferencing, CyberLink PowerDirector for video editing, portable video/photo cameras video/photo capturing and others) are now available through licensing or open source environments. Different technologies offer a variety of features which could be useful in a specific environment or community. The university should assess their eLearning needs, considering issues such as the culture of the community in adopting technologies with different complexities, cost-benefit implications, university-relevant technologies, the capacity of the existing infrastructure to support these as well as the availability of technical support. For universities in developing countries with limited funding resources, the use of open source technologies should be a priority.

The university should ensure that the ICT team has a sufficient number of technical staff to provide support to the entire community. Technical staff should be encouraged to undertake further training on new technologies under the sponsorship of the university.

Faculty and students should be well trained in content development once they know how to use content management platforms.

Monitoring and evaluation of eLearning is a key component in ensuring sustainability of any eLearning project and the effective use of technologies in line with educational goals. There should be a specific unit in the university's organizational structure to coordinate logistics for monitoring the use of eLearning, providing technical and non-technical support, and training, evaluating significant aspects of eLearning as well as coordinating periodic reviews of the policy and improvement of technologies. The unit should work closely with quality assurance committees to ensure that the design and delivery of online courses meets expected standards set by the university. 


\section{CONCLUSION}

This paper demonstrated that eLearning technologies can effectively be adopted to enhance the delivery of a health sciences competency based medical education at MUHAS. Therefore, eLearning, as a new educational management paradigm, has promising features for addressing the need for learner satisfaction within higher education while also ensuring that strategic imperatives of the institution are being fulfilled. MUHAS adopted a wide range of eLearning technologies including student academic records information system (SARIS), course management system (Moodle), digital institutional repository to enhance access to research and learning materials by using DSpace, online library catalogue to enhance access to bibliographic details of information resources, search tool for subscribed e-journals, e-books and other eresources, and other web 2.0 tools.

However, MUHAS experienced a number of challenges including inadequate numbers of computers, slow internet connectivity, electrical power outages, lack of awareness among students and faculty, and inadequate numbers of ICT technical staff. Generally, eLearning supported efforts to increase participation as it created learning environments that are student centred, free from the barriers of space and time at MUHAS. Therefore, sharing of knowledge and experience is vital for the success of elearning for higher education institutions in developing countries. Best practices and strategies in the area of eLearning and Web 2.0 should be adopted. Therefore, for successful implementation of eLearning, this paper recommends the following:

- The Universities should develop policies on ICT and eLearning issues for success implementation of learning technologies. Selection of technology for education should always consider pedagogy, technological cultural acceptance of the community and capacity of ICT infrastructure.

- The unit of ICT or eLearning should promote use of eLearning among the university community to raise awareness and bring enthusiasm for the use of technologies in education.

- The University should improve the ICT infrastructure including adequate numbers of computers, internet speed, and electrical power. The Universities should seek for alternative electrical power sources to ensure wide use of learning technologies

- $\quad$ The Universities must employ adequate number of skilled technical staff to ensure smooth running of the system.

- Universities should conduct training to technical ICT staff, faculty and students for effective implementation of learning technologies. Integrating eLearning and information literacy components into curricula facilitates a growth of interest among students for using technology in learning. Partnership between institutions with different levels of technological ambitions can be an important bridge to boost the growth of eLearning applications in the delivery of education among institutional partners.

\section{REFERENCES}

Afifi, G.M.H. (2011), "ELearning as an alternative strategy for tourism higher education in Egypt", Quality Assurance in Education, Vol. 19 No. 4, pp. 357-74.

Bakari, J., Mbwette, T.S.A. and Salaam, D.E. (2010), "Implementing eLearning in higher open and distance learning institutions in developing countries: the experience of the Open 
University of Tanzania", paper presented at the Fifth International Conference of Learning International Networks Consortium (LINC), Massachusetts Institute of Technology,

Cambridge, MA, 23 May.

Benninck, R., 2004. "Implementing ELearning from Corporate Perspectives". [Online] Knowledge Tree e-Journal. Available at:

http://knowledgetree.flexiblelearning.net.au/edition05/download/bennink.pdf [Accessed March 2011].

Bitew, G.D. (2008), “Using 'plasma TV' broadcasts in Ethiopian secondary schools: a brief survey", Australasian Journal of Educational Technology, Vol. 24 No. 2, pp. 150-67.

Carpan, C. (2010), "Introducing information literacy 2.0", College and Undergraduate Libraries,Vol. 17, pp. 106-13.

Casebeer, L., et al., 2008. "A Controlled Trial of the Effectiveness of Internet Continuing Medical Education". BioMed Central Medical Education, vol.6, pp. 37.

Childs, S., et al. , 2004. "Effective ELearning for Health Professionals and Student - Barriers and their Solutions. A Systematic Review of the Literature - Findings from the HeXL Project". Health Information and Libraries Journal, vol.22, pp. 20-32.

Chodorow, S. ,1996. "Educators must take the Electronic Revolution seriously". Academic Medicine, vol.71, pp. 221-26.

Choules, A. P. ,2007. "The use of ELearning in Medical Education: A Review of the Current Situation". Postgraduate Medical Journal, vol.83, pp. 212-216.

Curran, V., et al., 2006. "Evaluation of Learning Outcomes in Web- based Continuing Medical Education". Academic Medicine, vol.81, pp. 10.

Davis, J., et al., 2006. "Computer-based Teaching is as good as Face to Face Lecture-based Teaching of Evidence based Medicine: A Randomised Controlled Trial". BioMed Central Medical Education, vol.7, pp. 23.

Ezeani, C. N. (2011). Network literacy skills of academic librarians for effective services delivery: the case of University of Nigeria library system effective services delivery. Library Philosophy and Practice. Retrieved from http://unllib.unl.edu/LPP/ [Accessed July 26, 2012].

Frank, J. R., Mungroo, R., Ahmad, Y., Wang, M., De Rossi, S., \& Horsley, T. (2010). Toward a definition of competency-based education in medicine: a systematic review of published definitions. Medical teacher, 32(8), 631-7. doi:10.3109/0142159X.2010.500898

Frank, J. R., Snell, L. S., Cate, O. T., Holmboe, E. S., Carraccio, C., Swing, S. R., Harris, P., et al. (2010). Competency-based medical education: theory to practice. Medical teacher, 32(8), 638-45. doi:10.3109/0142159X.2010.501190

Grosseck, G. (2009), "To use or not to use Web 2.0 in higher education?", Procedia: Social and Behavioral Sciences, Vol. 1 No. 1, pp. 478-82.

Hamburg, I., Lindecke, C. \& Thij, H., 2003. "Social Aspects of ELearning and Blending Learning Methods". In: 4th European conference e-comm-line, Bucharest, Romania, 25-26 September 2003, Bucharest. 
Kaaya, E. \& Macfarlane, S., 2011. "Achievements of MUHAS-UCSF Academic Learning Project". In: MUHAS - UCSF Academic Learning Project, Universities in Transition for better Health Outcomes 2011 Conference. Dar Es Salaam, Tanzania, 19-20 October 2011, Dar Es Salaam: Muhimbili University of Health and Allied Sciences.

Kwanya, T., Stilwell, C., \& Underwood, P. (2012). The application of web 2 . 0 tools by libraries in Kenya : a reality check. SCECSAL XXth Conference from 4-8th June 2012 Nairobi, Kenya.

Lema, O. (2004), "Rural energy financing in Tanzania", Sustainable Energy and Development Forum Newsletter, No. 2, available at: www.tatedo.org (accessed 22 September 2011).

Leung, W., 2002. "Competency based Medical Training: Review". BMJ, vol.325, pp. 693-696.

Lwoga, E. T. ,2011. "Making Web 2.0 Technologies work for Higher Learning Institutions in Africa". Campus-Wide Information Systems, Vol. 29 Iss: 2 pp. 90 - 107

Ministry of Communication, Science and Technology, 2012. Design report: Last Mile Connectivity Project of Higher Learning and Research Institutions. Dar Es Salaam: Ministry of Communication, Science and Technology.

Muhimbili University of Health and Allied Sciences , 2011. MUHAS Academic Staff Database. Dar Es Salaam: Muhimbili University of Health and Allied Sciences.

Muhimbili University of Health and Allied Sciences , 2010. 2009 Tracer Study Report. Dar Es Salaam: Muhimbili University of Health and Allied Sciences.

Muhsin, H. K., 2008. The Using of ELearning Techniques to Improve the Medical Education. In: $3^{\text {rd }}$ International Conference on Information and Communication Technologies: From Theory Applications, Damascus, Syria, 2008, Damascus: ICTTA.

Muneja, P. S., \& Abungu, A. K. (2012). Application of Web 2 . 0 tools in Delivering Library Services : A Case of selected Libraries in Tanzania. SCECSAL XXth Conference from 4-8th June 2012 Nairobi, Kenya.

Ndume, V., Tilya, F. and Twaakyondo, H. (2008), "Challenges of adaptive elearning at higher learning institutions: a case study in Tanzania", International Journal of Computing and ICT Research, Vol. 2 No. 1, pp. 47-59.

Nichols, M. , 2003. "A Theory for ELearning". International Forum of Educational Technology and Society (IFETS), vol.6, no.2, pp. 1-10.

Rhema, A. and Miliszewska, I. (2010), "Towards eLearning in higher education in Libya”, Issues in Informing Science and Information Technology, Vol. 7, pp. 423-7.

Ruiz, J. G., Mintzer, M. J., \& Leipzig, R. M. (2006). The impact of ELearning in medical education. Academic medicine : journal of the Association of American Medical Colleges, 81(3), 207-12. Retrieved from http://www.ncbi.nlm.nih.gov/pubmed/16501260

Schönwald, I., 2003. Sustainable Implementation of ELearning as a Change Process at Universities. [Online] St.Gallen University, Available at: http://www.scil.ch/fileadmin/Container/Leistungen/ 
Veroeffentlichungen/buecher/2003-12-online-educa-schoenwald.pdf [Accessed 15 March 2012]

TUFTS, 2006. Introduction to TUSK. [Online] TUFTS, Available at: http://www.tufts.edu/med/education/md/curriculum/tuskintro.html [Accessed November 2011]

Unwin, T., et al. , 2010. "Digital Learning Management Systems in Africa: Myths and Realities". Open Learning: The Journal of Open, Distance and eLearning, vol.25, no.1, pp. 5-23.

Wiecha, J., et al., 2003. "Collaborative ELearning Using Streaming Video and Asynchronous Discussion Boards to Teach the Cognitive Foundation of Medical Interviewing: A Case Study". Journal of Medical Internet Research, vol.5, no.2.

Copyright for articles published in this journal is retained by the authors, with first publication rights granted to the journal. By virtue of their appearance in this open access journal, articles are free to use, with proper attribution, in educational and other non-commercial settings.

Original article at: http://ijedict.dec.uwi.edu//viewarticle.php?id=XXXX 